'symptoms until the end of the third month of pregnancy' and a history of three months' amenorrhoea is usually obtainable. On the other hand, with a haematocele the period of amenorrhoea is very much less. The haemorrhage with retrovcried gravid uterus is irregular and discontinuous. The clief point of distinction is to be found by examination. With retroversion of the uterus the cervix is tilted forwards and upwards, sometimes so much so that it is extremely difficult to reach it with the finger and the body of the uterus cannot be felt in its normal position, whereas with haematocele, though the nterus may be very much displaced forwards, the cervix will be directed downwards and the body can usually be distinguished above it.

The soft consistence of the tumour and its definite out. line are quite different from those of a haematocele.

Inflammatory affections present the greatest difficulties, and in many cases the diagnosis is impossible.

Pelvic cellulitis presents many points of similarity to haematocele, when the inflammatory mass forms behind the uterus. It tends to encircle the rectum in the same way. It is accompanied by febrile disturbance and it nsually originates in association with pregnancy. With cellulitis, however, the mass is more diffuse and firmer, and less rounded below, and the uterus, though fixed, is seldom much displaced from its normal position. Tho history, too, is different. Cellulitis almost always follows either a full-time labour or an abortion, and its onset is much more gradual, and is preceded by rise of temperature, whereas haematocele is acute in onset and the rise of temperature follows the formation of the tumour and scldom reaches to so great a height. An appendicular swelling is situated at a higher level, usually entirely above the pelvic brim, though it sometimes extends into the pelvis. It, again, is less defined. The constitutional disthrbance and rise of temperature are greater, and there is generally a history of intestinal disturbance. Occasionally tubal mole or haematocele is accompanied by diarrhoea presumably from irritation of the bowcl by pressure, and in these cases it is difficult to exclude appendicitis.

The condition which bears the closest resemblance to these chronic cases of ectopic gestation is undoubtedly salpingitis. Here not only the physical signs but also the symptoms and history may be very misleading. It is not unusual for an attack of salpingitis to be preceded by suppression of a menstrual pericd, while the onset of the attack is accompanied by more or less profuse vaginal haemorrhage. This history, together with the physical signs of a mass behind the uterus, is apt to be very confusing, and in some cases $I$ do not think it is possible to arrive a diagnosis without prolonged observation of the patient.

There are, however, several points of difference a consideration of which may be of great value in assisting in the diagnosis.

Salpingitis usually follows a labour at term or an abortion or an attack of gonorrhoeal vulvitis, and there will generally be a history of one of these. There are however, cases of chronic salpingitis which remain quiescent for long periods, occasionally lighting up and giving rise to acute symptoms. With these there will be no history of a recent cause, but it is generally possible to obtain a history of a similar attack in the past, or perhaps several similar attacks spread over a period of some years. It must not be forgotten that ectopic gestation may be a sequel to an old attack of salpingitis.

I have said that salpingitis may cause suppression or postponement of a menstrual period. The haemorrhage, when it occurs, is different from that due to ectopic gestation. It is usually much more profuse, and its colour is bright red, and it subsides after a week or ten days. In ectopic gestation the external haemorrhage is not severe, but continues for a long period-sometimes over many weeks-and is very dark in colour. With salpingitis there is also complete absence of a decidual cast. I regard this chronicity of the haemorrhage as the most important sign in doubtful cases.

Both conditions give rise to pyrexia, but that of salpingitis is, as a rule, very much higher than that of ectopic gestation. Of course many cases of salpingitis occur where the temperature never rises to any great height, but these must be regarded as the exceptions.

Signs of pregnancy, if present, are of course conclusive; but it must be remembered that most cases of ectopic gestation terminate very early, before the signs of pregnancy are at all well marked.

There are also one or two points of difference in the character of the tumour of the two cases. With salpingitis the tumour is, as a rule, central, both tubes being affected; and it is usually irregular in outline. Sometimes it is possible to trace the convolutions of the tubes bimanually, though they are generally obscured by peritubal inflamma. tion. On the other hand, a peritubal collection of blood is always single and almost always situated at the side of and behind the uterus. Examination in cases of salpingitis usually causes more pain, but this is not a very reliable feature.

Finally, there is one very important point. In cases of salpingitis the tendency is for resolution to occur quickly under appropriate treatment, and for the tumour to become rapidly absorbed. With haematocele there is also a tendency for absorption to occur, but this process is extremely slow.

I think that it may be safely said that if with a fortnight's treatment the tumour does not diminish in size and there are no signs of the presence of pus, a diagnosis of ectopic gestation may be made with confidence.

To sum up, salpingitis should be suspected in the presence of :

A history of previous similar attacks or of a recent source of infection.

Haemorrhage profuse but not persistent.

Considerable pyrexia.

Tumour irregular, central, and very tender.

Rapid resolution.

And haematocele may be diagnosed where there is :

No history of previous attacks and no recent source of

Where the haemorrhage is slight in amount but persistent. Where the haem
Pyrexia slight.

Pyrexia slight.

Very slow resolution.

Signs of pregnancy in breast, etc.

\section{ALBUMINURIA IN PREGNANCY.}

\section{HCGH M. RAVEN, M.R.C.S., L.R.C.P., BROADSTAIRS.}

OF all the cases which cause anxiety to the general practitioner, none cause more than those of albuminuria in pregnancy. I have been fortunate, or unfortunate, enough to have had the experience of three such during the past year, and I think that though they are not perhaps startling, they will be of interest. I am thankful to say that the three mothers and two babies are alive and well.

\section{CASE r.}

The first was a young woman aged 21 in her first pregnancy. I had vaguely suspected her because she had a puffy and pale aspect, ret I coald not find any albumen in the urine at several examinations. One evening towards the end of the ninth month I was called to her "in a hurry, and was alarmed to find considerable oedema of the legs and face, and that she was having an acute attack of epigastric pain and headache. She said that she thought she had caught a chill when in the scullery. Labour had not apparently commenced, and I hastened to give her a strong dose of calomel and jalap, and to order a hot pack, finding the urine full of albumen. She vomited the former, bui was eased somewhat by a dose of aspirin, which made her per. spire freely. Within a few hours I was called hurriedly by her nurse, and before I could get there the child the , and before 1 could get there the child was born, with (as the nurse described) only two violent labour pains, which to my surprise had not caused any laceration of the perineum or elsewhere. She went on quite well until about the sixth day, when she had a severe attack of neuralgia on the left side of the head, and almost complete left hemianaesthesia and some weakness of the left lower limb. She eventually made a quite satisfactory recovery, the anaesthesia taking two or three
months to pass off completely.

\section{CASE II.}

The second was a delicate primipara aged 38 . I was naturally anxious about her, but she had shown no signs of albuminuria. In this case labour came on at the eighth month, and was apparently progressing satisfactorily. Before the os uteri had fully dilated she suddenly had a severe convulsion. Luckily I was on the spot, and was able to give her chloroform immediately. A specimen of urine obtained by catheterization showed large quantities of albumen. She had another convulsion before she had fally come round from the anaesthetic, and with the 
help of a fellow-practitioner I performed version and delivered rapidly. The child was dead, and had a lower dorsal meningocele. This patient made a slow but uneventful recovery.

\section{CASE III.}

The third patient, also a primipara, aged 34, called me to see ber at the eighth month for severe epigastric pain. I found large quantity of albumen in the urine, although none had been present some weeks previously. Some opium quieted down the symptoms, and a fortnight's strict rest in bed, milk diet, careful purgation, and hot baths, considerably diminished the quantity of albumen and the of albumen; and the oedema which she had in her legs went down. In this case, especially as I suspected the pelvis of being of small size, I induced labour at the end of the fortnight by means of the insertion of a bougie; and when labour had progresser far enough for the os to be sufficiently dilated, gave chloroform, turned, and delivered a small living child. Both mother and child have done well, though the convalescence was rather slow.

Recent examinations of the urine from these three cases proved that the albumen has cleared up in all except the last.

I would especially draw attention to two interesting points in these cases: the variability of the presence of albumen previous to the symptoms, and the symptom of epigastric pain.

As a matter of routine I always examine the urine of women who engage me to attend them in confinement but it would seem that this examination has to be made at fairly frequent intervals to avoid being taken unawares by the advent of albumen. With regard to the sudden onset of pain in the epigastrium, I was put on my guard by my father many years ago, and feel very grateful to him for the hint. It does not seem to be mentioned with mucl emphasis in books on midwifery or known very widely among practitioners.

Two other cases of albuminuria in pregnancy have come under my notice in recent years. The first was an elderly primipara who had convulsions and lost her first child, bu recovered, herself; when, some yeazs afterwards, she asked me to attend her, she went through her labour satisfactorily after being kept on a careful diet after the fourth month, with fairly frequent administration of aperients. The other was a lady whom I saw convalescing from severe eclampsia and who still showed some partial aphasia, partial blindness in the left eye, and some anaesthesia of the hand. This patient suffers from chronic pyelitis.

Dr. Gowlland of Faversham has published in the St. Mary's Hospital Gazette, November, 1911, two terrible cases of haemorrhage, and another case of albuminuria with a fatal ending, all three with albuminuria in pregnancy. I am thankful to say that I have never met haemorrhage complicating these cases, but some years ago I lost an elderly primipara from internal bleeding after confinement, due, I think, to an extensive tear of the os uteri into the peritoneal cavity. I can remember feeling wofully helpless in trying to restore this poor woman, and to check the bleeding.

Dr. Pinniger of this town very kindly gave me the advantage of his help and advice in two of my cases.

\section{CHICKEN-POX DURING THE PUERPERIUM.}

\section{BERNARD MYERS, M.D.EDIN.,} HAMPSTEAD.

As the occurrence of chicken-pox during the puerperium is fortunately rare, I have been asked by an obstetrician to publish the following case :

A primipara, aged 30 , had an uneventful parturition. The A A rerium was normal also up to the tenth day. Then a puerperium was normal also up to the tenth day. Then a butcle, containing apparenty clear that, appean upon the right buttock. In a fiew hours a spots were not breast immediately below the nipple. These spots were not itchy. The temperature was raised to $99^{\circ} \mathrm{F}$; ; the patient remained cuite well in herself: As a married sister of hers was just convalescent from chicken-pox, I was on the look-out for any evidence of this complaint, more especially as my patient had kissed her sister three days before her confinement. I may mention that her sister was not aware at the time that she was suffering from chicken-pox, but her four children also subsequently developed the complaint, which they undoubtedly caught from their mother.

Twenty-four hours after the two initial spots manifested themselves the patient had a crop of spots on the chest and forehead which were typically chicken-pox. They were particu- larly itchy. The temperature rose to $101^{\circ} \mathrm{F}$. The lochial discharges, which had practically stopped three days previously, now reappeared. In the course of two or three clays from the appearance of the first spots the labia majora and b:easts were literally covered with pocks. There were several on each nipple. A fair number were also seen on the face, body, legs, neck, ears, eyelids, and palate. Although there were not many pocks on the legs, a good crop was seen on the perineum and around the anus. She looked and felt distinctly ill on the fourth day of the rash; the temperature remained at $101^{\circ} \mathbf{F}$.

Fearing that the first spot on the buttock might turn out to be chicken-pox I immediately stopped the child being fed by its mother ; it was weaned and brought to another room.

Althongh much troubled by the intensity and irritation of the spots on the vulva the mother mate an excellent recovery without any ill effects. Each spot was treated with 1 in 40 carbolic oil night and morning.

The baby developed a temperature of $100^{\circ} \mathrm{F}$. for three days after leaving its mother and showed a tiny papular erythema after leaving its mother and showed a tiny papular erythema upon its chest. It took its food well, had no vomiting or diarrhoea, and seemed to be quite undisturbed in any way br the rash, which vanished after four days. Was this an ator ive attack of chicken-pox? The little papules came out in crops, and the condition was not like any of the ordinary skin rashes which babies are subject to.

The peculiarities of the case, as far as the mother was concerned, were the predilection of the pocks for the labia majora and breasts, parts which were, one may presume, receiving a more generous blood supply due to her recent pregnancy than would otherwise obtain. The appearance of the first spot on the buttock was unusual. This spot, although at first unlike chicken-pox, subsequently went through the usual changes in a typical manner.

\section{Ettemaranda:}

\section{MEDICAL, SURGICAL, OBSTETRICAL.}

\section{ABSCESS OF THE SPLEEN COMPLICATING MALARIA.}

The report by Lieutenant MacGregor, in the JouRNAL of February 3rd, recalls a case I met with many years ago in India. It was that of a British soldier who had served some years in India, and was much broken"down by climate and service.

His final admission to hospital was for " ague," but after some weeks of irregular. fever, it developed a remittent character, and was, in fact; of a.more or less hectic type. This was long before the days of the microscope as an aid to diagnosis, and the true nature of the complaint was a matter. of much speculation. He grew gradually weaker, and then complained of a pain in the left side. This was more or less referred to the base of the lung, but there were no signs or symptoms of pneumonia. Some friction sounds were heard, and it was thought he might have some dry pleurisy about the base of the lung. The spleen was not much enlarged (as made out by palpation), in fact, much less so than might have been expected considering the duration of the fever. He died somewhat suddenly one night, and at the post-mortem examination multiple abscesses of the spleen were discovered, which had never been suspected.

The case made a great impression upon me at the time, as I had never heard of a similar one, nor have Isince, and, as noted by Lieutenant MacGregor, abscess of the spleen is not generally mentioned in textbooks. I could find no note at that time (it was in 1889 or 1890 at Lucknow). I write entirely from memory, which accounts for my somewhat "scrappy" notes. As a remarkable coincidence I may note that I quoted this very case when discussing rare and unusual cases with a medical friend this morning, only a few hours before reading Lieutenant MacGregor's case in the JourNat.

West Kensington, w. GEo. T. Mould, Major I.M.S. (ret.).

\section{NERVOUS RETENTION OF URINE.}

WiTH regard to the treatment of nervous retention of urine by injection of glycerine into the rectum, I should like to state that this treatment entirely failed in a recent case. A fortnight ago a married lady who has had two children, and who was curetted seven months ago, and who has been quite well since, consulted me for retention. This was complete, and I had to use the catheter daily. On the fifth day she was examined under chloroform by a gynaecologist. The pelvic organs were found healthy. 